\title{
Formulation and In vitro Evaluation of Carvedilol Transdermal Delivery System
}

\author{
Pisipati Aparna ${ }^{1 *}$, Lyadella Divya ${ }^{1}$, Kalva Bhadrayya ${ }^{2}$, Chavali VS Subrahmanyam ${ }^{1}$ \\ ${ }^{1}$ Department of Pharmaceutics, Osmania University, Gokaraju Rangaraju College of Pharmacy, Jawaharlal Nehru \\ Technological University, Hyderabad, ${ }^{2}$ Swaroop Tech Consultancy, Secunderabad, India.
}

*For correspondence: Email: aparna_16p@hotmail.com

\begin{abstract}
Purpose: To develop and optimize carvedilol transdermal delivery system.

Methods: Solvent casting method was used to prepare patches using polymethyl methacrylate (PMMA) and Eudragit E100 (EE100) polymers, dimethylsulfoxide (DMSO) penetration enhancer, dibutylphthalate (DBP) plasticizer and Tween 80 surfactant. A $2^{3}$ factorial design was used based on three variables (PMMA, EE100, DMSO). at two levels Second order polynomial equations indicating interplay of ingredients were obtained by factorial design using SigmaTech software for 1, 4, 8 and $20 \mathrm{~h}$ release data. so the design was extended to central composite design (CCD). The target formulation was obtained from contour plots and evaluated for various physicochemical parameters. including in-vitro dissolution studies.

Results: Curvature effect was observed in F1 to F8 formulations, highlighting the interplay of ingredients. The interaction term $\left(X_{2} X_{3}\right)$ exhibited highest Sum of Squares SS ratio at 1,4 , and $8 \mathrm{~h}$ data with positive coefficients indicating interaction; and so extended to CCD. From contour plots target formulation, F19, was identified and evaluated. The release data, were subjected to kinetic analysis, which followed Higuchi (diffusion) model $\left(R^{2}=0.9886\right)$.

Conclusion: F19 yielded release profile nearer to the theoretical predictions with $R^{2}$ of 0.9888 and followed Higuchi kinetics. Thus, a diffusion-mediated carvedilol matrix patch was successfully developed.
\end{abstract}

Keywords: Carvedilol, Central composite design, Drug release, Transdermal patch.

Tropical Journal of Pharmaceutical Research is indexed by Science Citation Index (SciSearch), Scopus, International Pharmaceutical Abstract, Chemical Abstracts, Embase, Index Copernicus, EBSCO, African Index Medicus, JournalSeek, Journal Citation Reports/Science Edition, Directory of Open Access Journals (DOAJ), African Journal Online, Bioline International, Open-J-Gate and Pharmacy Abstracts

\section{INTRODUCTION}

Continuous intravenous infusion is recognized as a superior mode of drug delivery not only to bypass first-pass elimination, but also to maintain a constant, prolonged, and therapeuticallyeffective drug level in the body. Such mode of drug delivery necessitates hospitalization of patients and close medical supervision of the medication. There has been an increasing awareness that the benefits of intravenous drug infusion can be closely duplicated (without its potential hazards) by transdermal administration [1]. Several transdermal drug delivery systems (TDDS) aiming to achieve systemic delivery have recently been developed.

Few drugs are already available as transdermal patches in the market for the treatment of angina, hypertension, menopausal syndrome, hypogonadism, motion induced nausea etc [2]. Carvedilol, a non selective $\beta$ - adrenergic blocker with $\alpha_{1}$ blocking activity, is one of the most widely 
Table I: Optimization designs for the development of carvedilol transdermal drug delivery system (TDDS)

\begin{tabular}{|c|c|c|c|c|}
\hline $\begin{array}{c}\text { Formulation } \\
\text { code }\end{array}$ & Treatment & $\begin{array}{c}\text { Level of PMMA, } \\
X_{1}(\mathrm{mg})\end{array}$ & $\begin{array}{l}\text { Level of Eudragit } \\
\text { E 100, } X_{2}(\mathrm{mg})\end{array}$ & $\begin{array}{c}\text { Level of DMSO, } \\
X_{3}(\mathrm{mg})\end{array}$ \\
\hline F1 & 1 & $-1(200)$ & $-1(40)$ & $-1(60)$ \\
\hline $\mathrm{F} 2$ & $X_{1}$ & $+1(300)$ & $-1(40)$ & $-1(60)$ \\
\hline F3 & $x_{2}$ & $-1(200)$ & $+1(120)$ & $-1(60)$ \\
\hline $\mathrm{F} 4$ & $X_{1} X_{2}$ & $+1(300)$ & $+1(120)$ & $-1(60)$ \\
\hline F5 & $x_{3}$ & $-1(200)$ & $-1(40)$ & $+1(100)$ \\
\hline F6 & $\mathrm{X}_{1} \mathrm{X}_{3}$ & $+1(300)$ & $-1(40)$ & $+1(100)$ \\
\hline F7 & $\mathrm{X}_{2} \mathrm{X}_{3}$ & $-1(200)$ & $+1(120)$ & $+1(100)$ \\
\hline F8 & $\mathrm{X}_{1} \mathrm{X}_{2} \mathrm{X}_{3}$ & $+1(300)$ & $+1(120)$ & $+1(100)$ \\
\hline F9-F12 & Midpoint & $0(250)$ & $0(80)$ & $0(80)$ \\
\hline F13 & $+2 X_{1}$ & $+2(350)$ & $0(80)$ & $0(80)$ \\
\hline F14 & $-2 X_{1}$ & $-2(150)$ & $0(80)$ & $0(80)$ \\
\hline F15 & $+2 X_{2}$ & $0(250)$ & $+2(160)$ & $0(80)$ \\
\hline F16 & $-2 X_{2}$ & $0(250)$ & $-2(0)$ & $0(80)$ \\
\hline F17 & $+2 X_{3}$ & $0(250)$ & $0(80)$ & $+2(120)$ \\
\hline F18 & $-2 X_{3}$ & $0(250)$ & $0(80)$ & $-2(40)$ \\
\hline
\end{tabular}

Key: Formulations F1 - F 8 are factorial design, $2^{3}$; formulations $F 9-F 12$ (midpoints) are for statistical analysis; formulations F13 - F18 are star points of central composite design; Other ingredients are: dibutyl phthalate (80 mg), Tween 80 (16 mg) and carvedilol (80 mg).

prescribed drugs in the management of hypertension [3]. Low oral bioavailability (25\%) due to extensive first pass metabolism, a short plasma half-life $(6 \mathrm{~h})$ and the long term usage made carvedilol an ideal drug for transdermal route of administration [3-5]. Furthermore, the low molecular weight (406.5), log $P$ (4.19), log $\mathrm{pK}_{\mathrm{a}}$ (7.9), low dose 25-50 mg and low melting point $114{ }^{\circ} \mathrm{C}$ confers on the drug ability for it to be easily absorbed through the skin.

Polymers selected include polymethyl methacrylate, for its rate controlling attribute and Eudragit E100 for its swelling [6]. Reports are available on the use of polymethyl methacrylate and Eudragit E100 for the preparation of transdermal (TD) patches individually, but not in a combination till date $[7,8]$.

The aim of the present study was to develop and optimize a suitable TDDS of carvedilol using $2 \mathrm{x}$ 3 factorial central composite design.

\section{EXPERIMENTAL}

\section{Materials}

Carvedilol was a gift from Aurobindo Pharmaceuticals, Hyderabad. Eudragit E100 was a gift from Strides Arco Labs Pvt Limited, Bangalore. Polymethylmethacrylate (PMMA) was purchased from Himedia laboratories, Mumbai,
India. All the other chemicals were obtained from SD Fine Chemicals.

\section{Drug/excipient compatibility studies}

To ascertain the compatibility between carvedilol and excipients, differential scanning calorimetry DSC studies were carried out on carvedilol, PMMA, EE100 and a physical mixture of these three components $(1: 1: 1)$ using a dynamic DSC (Shimadzu DSC-50 Thermal Analyzer) in nitrogen atmosphere at the heating rate of 5 ${ }^{\circ} \mathrm{C} / \mathrm{min}$. Fourier transform - infrared (FT-IR) studies (Shimadzu, Japan) were also carried out on carvedilol, PMMA, EE100 and their physical mixture.

\section{Preparation of TDDS}

Transdermal patches were prepared by casting method on a petriplate by solvent evaporation [9]. All the ingredients were dissolved in chloroform individually, mixed with the polymers dispersion and poured in petriplates. Then the plasticizer, surfactant and penetration enhancer were added and mixed. Prepared polymeric dispersion was poured on a petriplate of $71 \mathrm{~cm}^{2}$ area and was covered with inverted funnel (to control evaporation of solvent and avoiding cracking and breaking of patch) and allowed to dry overnight. The dried patches were removed and stored in a dessicator. Concentrations of 
PMMA, EE100 and DMSO were varied as per the design, and patches were observed for flexibility and other properties.

\section{Formulation design of carvedilol TDDS}

Preliminary investigation based on trial and error, experiments yielded an empirical formulation. Design of experiments (DOE) was attempted using $2^{3}$ factorial design [10]. Three variables at two levels and with actual values were represented in Table I. The levels of all other ingredients in the formulation were fixed and the basic plan was identified. Other ingredients (fixed) were; carvedilol $(80 \mathrm{mg})$, dibutylphthalate (80 mg), Tween-80 (16 mg) and chloroform (15 $\mathrm{ml}$ ). Midpoints (code 0 ) were also considered, so that errors can be estimated and statistical analysis was attempted and the analysis yielded a curvature effect. Thus, a composite design with additional 6 formulations was conducted.

\section{Central composite design}

As per the principles of central composite design, six formulations were added, by extending to five levels $(-2,-1,0,+1$ and +2$)$ [11]. The variables and levels along with detailed design with actual values are reported in Table I.

\section{Evaluation of transdermal patches}

The transdermal patches were evaluated for the following physicochemical parameters [12, 13].

\section{Thickness}

The thickness of the transdermal patches was measured using a screw gauge at different points on the patch and average thickness was calculated.

\section{Weight variation}

Ten patches of $1 \mathrm{~cm}^{2}$ were weighed using digital balance (Schimadzu, Japan) and the average weight was calculated.

\section{Folding endurance}

Folding endurance was determined by folding and opening the patch at the same place repeatedly until it breaks. The result was expressed as a number.

\section{Moisture content determination}

Patches $(n=10)$ were weighed individually and kept in a dessicator (calcium chloride) at room temperature for $24 \mathrm{~h}$ and the weight at various intervals during the period was noted, until there was no further loss in weight. The moisture content was calculated as $\%$ weight loss.

\section{Moisture uptake test}

The films $(n=3)$ were weighed accurately and placed in a dessicator of $75 \% \mathrm{RH}$ maintained using saturated solution of sodium chloride. After three days, the films were weighed and the moisture uptake was calculated as the \% difference between the final and initial weights with respect to initial weight.

\section{Drug content determination}

Transdermal patches were cut into pieces of $1 \mathrm{x}$ $1 \mathrm{~cm}^{2}$ and carvedilol content was determined $(\mathrm{n}=$ 3). A patch of $1 \mathrm{~cm}^{2}$ was taken into a $50 \mathrm{ml}$ beaker and $10 \mathrm{ml}$ of methanol was added and shaken for $5 \mathrm{~min}$. One $\mathrm{ml}$ was taken and diluted to $5 \mathrm{ml}$ with phosphate buffer $(\mathrm{pH} 7.4)$ and carvedilol content determined spectrophotometrically at $285 \mathrm{~nm}$ in the concentration range of $5-30 \mu \mathrm{g} / \mathrm{ml}$.

\section{In vitro release studies}

Carvedilol release from the transdermal system was evaluated using the USP paddle over disc dissolution apparatus prescribed for TDDS [14, 15a]. The dissolution test apparatus was thermostated at $32 \pm 0.5{ }^{\circ} \mathrm{C}$ and stirred at 50 rpm. The film was fixed on inverted glass petriplate using cyanoacrylate adhesive allowing drug to release only from upper surface and was placed at the bottom of the vessel containing 500 $\mathrm{ml}$ of phosphate buffer, $\mathrm{pH} 7.4$. Aliquots of $5 \mathrm{ml}$ of sample were withdrawn at every half an hour up to $2 \mathrm{~h}$, and thereafter periodically upto $24 \mathrm{~h}$, replacing with equal volume of buffer. The samples were analyzed spectrophotometrically at $285 \mathrm{~nm}$. Cumulative carvedilol released was calculated. Triplicate determinations were carried out.

\section{Data analysis}

The analysis of factorial design and central composite design was attempted using Sigmatech software (Swarooptech, Hyderabad, India). The software has built in statistical analysis, standard error of the estimate, error of variance, standard deviation, $\mathrm{F}$ distribution test, and orthogonal functions evaluation. The analysis output gave a print out of a table containing sum of squares and coefficients. A second order equation was written from the coefficients. Further contour plots were generated based on second order equations for analysis.

\section{RESULTS}

\section{Physical properties of carvedilol TDDS}

The texture and tackiness of the patches were satisfactory. The thickness of the patches ranged 
from 33 to $50 \mu \mathrm{m}$ and varied with the composition of patches. The average weight of films of $1 \mathrm{~cm}^{2}$ ranged from $60-87 \mathrm{mg}$ and was proportional to the dry weight of the ingredients. Folding endurance varied from 32 - 70, and inversely proportional to PMMA concentration. Moisture content and uptake were related to the concentration of EE100 to a large extent. Carvedilol drug loading varied from 95 to $98 \%$.

\section{In vitro drug release}

Carvedilol release over a $24 \mathrm{~h}$ period is shown in Fig 1.

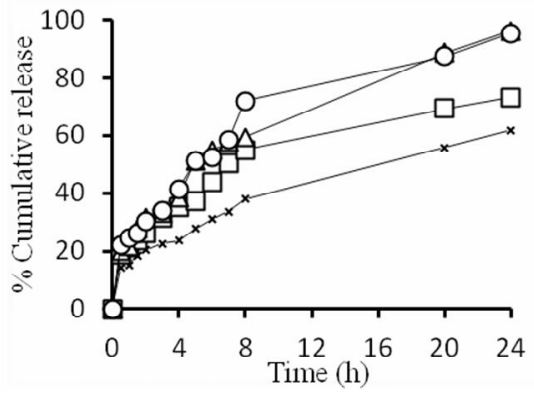

Figure 1: In vitro carvedilol release profile from different TDDS systems. Key: $\mathrm{X}=$ Fmid; $\square=\mathrm{F} 14 ; \Delta=$ Ftarget; o = F7

The concentrations of EE100 and DMSO were highest while that of PMMA was lowest for F7 and so reported higher release of $95 \%$. The release of carvedilol at the midpoints $(62 \%)$ was repeated four times (F9 - F12) for the purpose of statistical evaluation. $\mathrm{F} 14$ has shown a release of $73 \%$. The carvedilol release in F19 (Target) $(88 \%)$ was achieved nearest to the predicted value $(24 \mathrm{~h})$, and is presented in Fig 1 (Ftarget). The dissolution data of $24 \mathrm{~h}$ was suitably divided into four parts 1, 4, 8 and $24 \mathrm{~h}$ and analysis was attempted with the polynomial equations obtained given in the Table 2. This approach was similar to oral controlled drug delivery of metoprolol succinate of USP [15b]. Though the present formulation was TDDS, this analysis adopted the same time frame.

Cumulative carvedilol release was abstracted from all 12 formulations and the responses were analyzed as per the factorial design using SigmaTech software. The central composite design was planned by including two more levels, +2 and -2 for all the three variables [11]. Thus six more formulations were developed (Table I, F13 to F18) formulated and evaluated for physical parameters and for in vitro carvedilol release (F13 to $F 18)$.

\section{Central composite design - contour plot analysis}

For all 18 formulations, carvedilol release data were compiled and analyzed for $1,4,8$ and $20 \mathrm{~h}$ time points through contour plots [11]. Since the central composite design had three variables, it was necessary to keep one variable as constant and correlate other two variables. After extensive analysis of contour plots, it was decided to keep $\mathrm{X}_{3}$ (DMSO) at $80 \mathrm{mg}$, and $\mathrm{X}_{1}$ (PMMA) and $\mathrm{X}_{2}$ (EE100) plots were analyzed. For finalizing the composition, formulationcriteria (in vitro carvedilol release) was fixed as follows: $1 \mathrm{~h}-23 \%$, $4 \mathrm{~h}-30-40 \%, 8 \mathrm{~h}-55-60 \%$ and $20 \mathrm{~h}-80 \%$. For $1 \mathrm{~h}$ data analysis, contour plot $\left(\mathrm{X}_{1}\right.$ vs $\left.\mathrm{X}_{2}\right)$ was recorded in Fig $2 a$. For the given criteria, polymers were identified as (150 mg (PMMA), $40 \mathrm{mg}$ (Eudragit E100) of $\mathrm{X}_{1}$ (PMMA) and $\mathrm{X}_{2}$ (Eudragit E100) (Fig 2a). From 4 h data, contour

Table 2: Polynomial equations as per factorial design $\left(2^{3}\right)$

\begin{tabular}{|c|c|c|c|c|}
\hline $\begin{array}{l}\text { In-vitro } \\
\text { release } \\
\text { time (h) }\end{array}$ & $\begin{array}{l}\text { Polynomial } \\
\text { equation }\end{array}$ & $\begin{array}{c}\text { Equation } \\
\text { no. }\end{array}$ & $\begin{array}{c}\text { Contribution of } \\
\text { interaction terms, \% }\end{array}$ & $\begin{array}{c}\text { Curvature } \\
\text { effect }^{*}\end{array}$ \\
\hline 1 & $\begin{array}{l}y=23.4905-0.4177 X_{1}+0.09 X_{2}+0.1722 X_{1} X_{2} \\
-0.0322 X_{3}-0.6735 X_{1} X_{3}+0.7478 X 2 X 3+ \\
0.522 X 1 X 2 X 3\end{array}$ & 1 & $87.75 \%$ & $\begin{array}{l}-11.5458 \text { to } \\
-3.0783 \\
\text { Significant }\end{array}$ \\
\hline 4 & $\begin{array}{l}y=31.6375-0.9485 X_{1}+1.6125 X_{2}-1.6345 X_{1} X_{2} \\
+1.2992 X_{3}-1.0777 X_{1} X_{3}+2.8003 X_{2} X_{3}- \\
0.2468 X_{1} X_{2} X_{3}\end{array}$ & 2 & $69.34 \%$ & $\begin{array}{l}-8.4037 \text { to - } \\
7.8203 \\
\text { Significant }\end{array}$ \\
\hline 8 & $\begin{array}{l}y=48.2442-4.3632 X_{1}+1.7823 X_{2}-3.5422 X_{1} X_{2} \\
+3.9195 X_{3}-2.184 X_{1} X_{3}+4.224 X_{2} X_{3}- \\
3.7045 X_{1} X_{2} X_{3}\end{array}$ & 3 & $56.53 \%$ & $\begin{array}{l}-12.3617 \text { to } \\
-8.0838 \\
\text { Significant }\end{array}$ \\
\hline 20 & $\begin{array}{l}y=59.9973-6.6635 X_{1}+3.255 X_{2}- \\
5.6662 X_{1} X_{2}+4.0088 X_{3}-1.581 X_{1} X_{3}+ \\
2.5115 X_{2} X_{3}-3.5838 X_{1} X_{2} X_{3}\end{array}$ & 4 & $43.95 \%$ & $\begin{array}{l}-5.741 \text { to } \\
-2.8465 \\
\text { Moderately } \\
\text { significant }\end{array}$ \\
\hline
\end{tabular}


Table 3: Carvedilol release from TDDS target formulation (F19)

\begin{tabular}{cccc}
\hline $\begin{array}{c}\text { Time } \\
\text { (h) }\end{array}$ & $\begin{array}{c}\text { Theoretical, } \\
\text { (\% Cumulative carvedilol release from } \\
\text { contour plot) }\end{array}$ & $\begin{array}{c}\text { Experimental, } \\
\text { (\% Cumulative carvedilol } \\
\text { release) }\end{array}$ & Error (\%) \\
\hline 1.0 & 24 & $21.503 \pm 0.360$ & 10.404 \\
4.0 & 32 & $38.476 \pm 0.573$ & -20.237 \\
8.0 & 55 & $59.229 \pm 0.458$ & -7.27 \\
20.0 & 88 & $88.460 \pm 2.759$ & -0.5227 \\
\hline
\end{tabular}

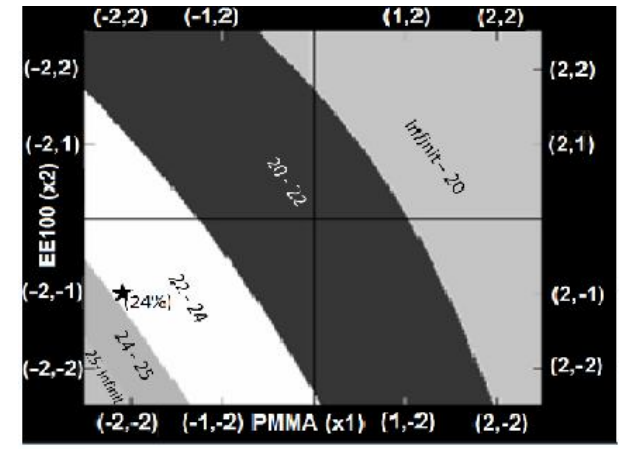

(a)

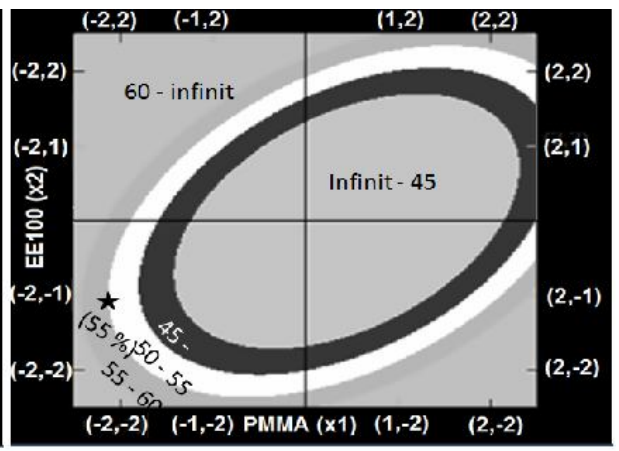

(b)

Figure 2: $X_{1}$ vs $X_{2}$ contour plot from central composite design. (a) $1 \mathrm{~h}$ release and (b) $8 \mathrm{~h}$ release. $\mathrm{X}_{3}$ (DMSO) was constant. Target formulation, PMMA-150 mg (code -2), Eudragit E100 - 40 mg (code -1) and DMSO - 80 $\mathrm{mg}$ (code -0).

plot $\left(X_{1}\right.$ Vs $\left.X_{2}\right)$ indicated the point (150 mg (PMMA), $40 \mathrm{mg}$ (Eudragit E100). These conclusions were agreeing with $1 \mathrm{~h}$ data analysis. For $8 \mathrm{~h}$ data analysis, contour plot $\left(\mathrm{X}_{1}\right.$ Vs $\mathrm{X}_{2}$ ) was recorded in Fig $2 \mathrm{~b}$. The plots are peak and mounds. The optimal point must be at the top or round. A small change in the variables produced a drastic change in the response. In such a case, the optimized parameters must be critical. For the expected release of carvedilol, the point $(-2,-2)$ i.e., $150 \mathrm{mg}$ PMMA and $40 \mathrm{mg}$ of Eudragit E100 respectively, were selected. $X_{1}$ and $X_{2}$ are codes and -2 and -1 are levels of $X_{1}$ and $X_{2}$ respectively. Equations contained codes. These can be levels such as $-2,-1,0,+1,+2$ etc., of $X_{1}$ and $X_{2}$ (Fig 2b) were selected. For 20 $h$ data, contour plot $\left(X_{1} V s \quad X_{2}\right)$ indicated curvilinear or nearly straight line. For the expected release of carvedilol (80 to $90 \%$ ), point (150 mg (PMMA), 40 mg (Eudragit E100) was chosen Any desired level can be an input for obtaining the desired response (dissolution). After obtaining the codes for target, these were translated into absolute values (Table 3).

\section{DISCUSSION}

The swelling and permeability of EE100 and penetration enhancer might be responsible for the release of carvedilol. The release of carvedilol was almost uniform in the initial $30 \mathrm{~min}$ in all the formulations, approximately $20 \%$ release and no burst effect observed. Evaluation of release pattern was suitably divided on hourly basis and was evaluated as following.

The first hour release data was analyzed and represented as a polynomial equation. The contribution of variables independently has no influence on the carvedilol release. The interaction of $\mathrm{X}_{2} \mathrm{X}_{3}$ was highest with SS ratio (37.3 $\%)$ and a positive sign of the coefficient $(0.7478)$. It indicated that the higher the amount of $X_{2}$ and $X_{3}$, the greater the carvedilol release. This was reasonable, because EE100 control the release and DMSO promote the carvedilol release. Interaction terms (\%SS ratio $\mathrm{X}_{1} \mathrm{X}_{2}, \mathrm{X}_{2} \mathrm{X}_{3}, \mathrm{X}_{1} \mathrm{X}_{3}$ and $X_{1} X_{2} X_{3}$ ) contributed approximately $88 \%$ and thus curvature effect was found significant.

The fourth hour release data was analyzed and represented in polynomial equation 2 (Table II). The interaction term $\mathrm{X}_{2} \mathrm{X}_{3}$ was the highest SS ratio $(46.479 \%)$ with a positive sign of the coefficient (2.8003) indicated direct relation between components and carvedilol release. The contribution of interaction terms was approximately $70 \%$. Finally, it was concluded that curvature effect was predominant. The results were nearly same as that of $1 \mathrm{~h}$ analysis.

The eight hour release data was analyzed and represented as a polynomial equation. The interaction term of $X_{2} X_{3}$ was the highest with SS 
ratio $(20.63 \%)$ with positive sign of the coefficient (4.2238). The contribution of interaction terms was to the tune of $57 \%$ and curvature effect was predominant. The results were nearly same as that of $1 \mathrm{~h}$ and $4 \mathrm{~h}$ data analysis.

The $20 \mathrm{~h}$ release data was analyzed and also represented as a polynomial equation. PMMA $\left(X_{1}\right)$ had the highest SS ratio $(35.80 \%)$ with a coefficient of negative sign (-6.6635), because PMMA was the release retardant. The contribution of interaction terms was approximately $44 \%$. Finally it was concluded that curvature effect was moderate and hence factorial design is inadequate. The time phased analysis indicated consistently curvature effect. Hence, factorial design was not sufficient and so central composite design was attempted for obtaining the target formulation.

Evaluation of the physical characteristics of the patches were satisfactory. In vitro carvedilol release of F14 was nearest to the expected $24 \mathrm{~h}$ release with PMMA content was at the lowest (-2 level) in F14.

Contour plots permitted the composition PMMA as $150 \mathrm{mg}(-2)$, EE100 as $40 \mathrm{mg}(-1)$ and DMSO as $80 \mathrm{mg}$; all the other ingredients in the formulation remained the same. Then transdermal patches were casted successfully and observed for thickness, weight, folding endurance, moisture content and moisture uptake and were found satisfactory. Carvedilol content was found to be $98.61 \%$. A transdermal patch of size $3.80 \mathrm{~cm}^{2}$ containing $4.14 \mathrm{mg}$ carvedilol was utilized for in vitro carvedilol release studies and the data of F19 was reported in Fig. 1. The release of carvedilol was $20 \%$ in the initial $30 \mathrm{~min}$ and was considered to be necessary, so as to improve the initial carvedilol absorption through skin. Then, the release must be linear, so as to maintain the levels of carvedilol. The theoretical and observed release of carvedilol target patch was reported in Table 3 together with the error.

Thus the target formulation (F19) showed predicted carvedilol release which fitted first order release kinetics. However, the release profile of the prepared patches followed Higuchi's equation indicating that permeation of drug from the patches was governed by diffusion mechanism. As many release processes can be represented by a coupling of Fickian and nonFickian mechanism. Ritger and Peppas introduced the power law equation $\mathrm{M}_{\mathrm{t}} / \mathrm{M}_{\infty}=\mathrm{Kt}^{n}$ to characterize the controlled release behavior of a drug from polymer matrices [16]. The $n$ value ( $n$
$=0.4376$ ) obtained on the present study indicates that the amount of drug released by Fickian diffusion predominated. So it can be concluded that the release of drug was a diffusion-dominated mechanism.

\section{CONCLUSION}

A matrix type TDDS of carvedilol was successfully developed using casting method. PMMA and EE100 were compatible with carvedilol. The factorial design (12 formulations) exhibited curvature effect. The transdermal patches exhibited good physical properties as well as suitable release. Second order equations representedcontour plots and were analyzed for obtaining the target formulation. The target formulation gave satisfactory in vitro carvedilol release over a $24 \mathrm{~h}$ period

\section{ACKNOWLEDGEMENT}

The authors thank Aurobindo Pharmaceuticals, Hyderabad, for the gift of carvedilol. Thanks are due also to Dr. PR Sateesh Babu, Associate Professor, GRCP, for his valuable contributions to the study.

\section{REFERENCES}

1. Chien YW. Novel Drug Delivery Systems. $2^{\text {nd }}$ edn. New York: Marcel Dekker Inc; 1992; pp 301-380.

2. Chien YW. Implantable therapeutic systems. In: Robinson, J.R.; Vincent HL. Editors. Controlled Drug Delivery Fundamentals and Applications. New York: Marcel Dekker Inc; 1987; pp 523-552.

3. The Merck index. An Encyclopedia of Chemicals, Drugs and Biologicals, $14^{\text {th }}$ edn. New Jersey: Merck research laboratories; 2006.

4. Anthony CM, David O, Brian W. editors. Clarke's Analysis of Drugs and Poisons, $3^{\text {rd }}$ ed. Mumbai: KM Varghese company; 2004; $p 760$

5. Udhumansha $U$, Reddy MVS, Kumaresan R, Farhan JA Roop KK. Transdermal therapeutic system of carvedilol: Effect of hydrophilic and hydrophobic matrix on in vitro and in vivo characteristics. AAPS Pharm Sci Tech 2007; 8(1): E1-E8.

6. Raymond, C.R.; Paul, J.S.; Sian, C.O. Hand book of Pharmaceutical Excipients. $5^{\text {th }}$ ed. London: The Pharmaceutical Press; 2006; pp 551-560.

7. Shams MS, Alam MI, Ali A, Sultana $Y$, Aqil $M$. Pharmacodynamics of losartan transdermal system for the treatment of hypertension. Drug Dev Ind Pharm 2010; 36(4): 385-392.

8. Paola M, Francesco C, Leila T, Antonella C, Luisa M. Design of a new water soluble pressure sensitive adhesive for patch preparation. AAPS Pharma Sci Tech 2003; 4(1)1-9.

9. Sanjay JK, Mangesh RB, Santosh KM. Development and evaluation of carvedilol loaded transdermal drug delivery system: in vitro and in vivo characterisation study. Drug Dev Ind Pharm 2012; 38(12): 1530-1537.

10. Sanford B, Charles B. Pharmaceutical Statistics Practical and Clinical Applications. $4^{\text {th }}$ ed. New York: Marcel Dekker, Inc; 2004; pp 506-539. 
11. Gunjeet K, Goutham R, Hemraj H, Amith KG. Optimisation of protocell of silica nanoparticles using $3^{2}$ factorial design. AAPS Pharm Sci Tech 2012; 13(1): 167-173

12. Sashikant DB, Mrugendra BP. Formulation of transdermal patch of carvedilol by using novel polymers. Der Pharmacia Scinica 2011; 2(2): 185189.

13. Saxena M, Mutalik S, Reddy MS. Formulation and evaluation of transdermal patches of metochlopromide hydrochloride. Indian Drugs 2006; 43(9): 740-745.

14. Aquil M, Bhavana, Chowdhary I, Sultana Y, Talegaonkar S, Ahmad FJ, Ali MM. Transdermal therapeutic syytem of enalapril maleate using piperidine as penetration enhancer. Curr Drug Deliv 2008; 5(2): 148-152.

15. United States of Pharmacopoeia 26 NF 21. Toranto: The United States of Pharmacopoeial Convention; 2003a. 2161; 2003b. 1221.

16. Ritger PL, Peppas NA. A simple equation for description of solute release, I: Fickian and non-Fickian release from non-swellable devices in the form of slabs, spheres, cylinders or discs. J Control Release 1987; 5: 23-26. 